\title{
Physical, optical and structural studies of copper-doped lead oxychloro borate glasses
}

\author{
K CHANDRA SEKHAR ${ }^{1, *}{ }^{1}$, ABDUL HAMEED ${ }^{1}$, VASANT G SATHE ${ }^{2}$, M NARASIMHA CHARY ${ }^{1}$ \\ and MD SHAREEFUDDIN ${ }^{1}$ \\ ${ }^{1}$ Department of Physics, Osmania University, Hyderabad 500007, India \\ ${ }^{2}$ UGC-DAE Consortium of Scientific Research, Khandwa Road, Indore 452017, India \\ *Author for correspondence (chandu_07u@ yahoo.co.in)
}

MS received 10 July 2017; accepted 8 November 2017; published online 23 May 2018

\begin{abstract}
Bluish coloured glasses are obtained from the composition $\mathrm{PbCl}_{2}-\mathrm{PbO}-\mathrm{B}_{2} \mathrm{O}_{3}$ doped with $\mathrm{Cu}^{2+}$ ions. Basic physical properties and spectroscopic studies (optical absorption, electron paramagnetic resonance, Fourier transform infrared and Raman spectroscopies) were carried out on these samples. The increase in $\mathrm{PbCl}_{2}$ content resulted in the decrease in density and increase in molar volume. At optical frequencies, band gaps and Urbach energies were evaluated and their variation is explained. Spin-Hamiltonian parameters (SHP) obtained from the EPR spectra suggest that the ligand environment around $\mathrm{Cu}^{2+}$ is tetragonally distorted octahedral sites and the orbital $d_{x^{2}-y^{2}}$ is the ground state. The characteristics broad bands in the optical absorption spectra are assigned to the ${ }^{2} \mathrm{~B}_{1 \mathrm{~g}} \rightarrow{ }^{2} \mathrm{~B}_{2 \mathrm{~g}}$ transition. The bonding coefficient values were evaluated using optical data and SHP. FTIR studies suggested that the glass structure is built up of $\mathrm{BO}_{3}$ and $\mathrm{BO}_{4}$ units. The presence of diborate, pyroborate, pentaborate groups, etc. in the glass network was confirmed from Raman spectra.
\end{abstract}

Keywords. Lead borate glasses; ionic radius; electro negativity; spin-Hamiltonian parameters; FTIR; Raman spectra.

\section{Introduction}

Due to the flexibility in the composition and with extremely interesting properties have made the glasses to attract many researchers. The importance of borate glasses increased in the last few decades, because they exhibit exclusive unique properties like durability, reduced thermal expansion, resistant to thermal shocks, enhanced toughness, chemical resistance, transparency, etc. Three-dimensional borate networks consist of $\mathrm{BO}_{3}$ triangles and $\mathrm{BO}_{4}$ tetrahedra. Glasses prepared with heavy metal oxide, such as $\mathrm{PbO}, \mathrm{CdO}, \mathrm{BaO}$ have shown relatively high index of refraction, density and transparency in IR radiation, etc. $[1,2]$. The addition of heavy metal oxides to the borate glass system increases the Raman scattering cross-section by several folds, thus, stimulating the interest in the complex systems [3]. Among the most metallic oxide glasses, lead oxide $(\mathrm{PbO})$ glasses are unique. Even though the element lead is toxic, $\mathrm{PbO}$ plays an important role in the glass formation and has several advantages. $\mathrm{PbO}$ not only influences the structure, but also plays the dual role of modifier/former based on its concentration. At low concentration $(<40 \mathrm{~mol} \%), \mathrm{PbO}$ behaves as network modifier in which $\mathrm{Pb}-\mathrm{O}$ bond is ionic, while at higher concentration $(>40$ $\mathrm{mol} \%), \mathrm{PbO}$ acts as network former, where $\mathrm{Pb}-\mathrm{O}$ bond is covalent [4-7]. Oxyhalide glasses are quite important for applications as host materials in high power laser systems. The inclusion of $\mathrm{PbO}$ and $\mathrm{PbX}_{2}(\mathrm{X}=\mathrm{F}, \mathrm{Cl}$ and $\mathrm{Br})$ in the borate composition resulted in creating $\mathrm{BO}_{3}$ and $\mathrm{BO}_{4}$ units with the further considerable increase in transparency in IR radiation, high refractive index and optical nonlinearities. Lead glasses with halides have special optical properties leading to applications in modern optical devices, such as laser engineering and drawing of optical fibres [8-11]. Electron paramagnetic resonance (EPR) technique can present extensive knowledge about the microscopic local environment of the transition metal (TM) ions in glasses, which in turn are influenced by the local structure. The existence of TM ions in more than two valency states has attracted the attention of many researchers to dope the glasses with TM ions. Of the TM ions, copper has simple EPR spectrum and gives useful structural information about the ligands surrounding the $\mathrm{Cu}^{2+}$ ion in glass. Incorporation of paramagnetic ions such as $\mathrm{Cu}^{2+}$ enhances the applications of glasses towards memory and switching devices $[12,13]$. Keeping in view of the applications of halide glasses, the authors have investigated the physical, optical and structural studies of lead chloroborate glasses containing $\mathrm{Cu}^{2+}$ ions.

\section{Experimental}

Conventional melt-quenching method is used to prepare the glasses with $x \mathrm{PbCl}_{2}-(30-x) \mathrm{PbO}-69 \mathrm{~B}_{2} \mathrm{O}_{3}-1 \mathrm{CuO}$ (PCPBC) (where $x=5,10,15,20$ and $25 \mathrm{~mol} \%$ ) composition. Analar 
Table 1. Density $(\rho)$, molar volume $\left(V_{\mathrm{m}}\right)$, optical band gap $\left(E_{\mathrm{opt}}, \mathrm{eV}\right)$, refractive indices $(n)$, molar refraction $\left(R_{\mathrm{m}}\right)$ and molar electronic polarizability $\left(\alpha_{\mathrm{m}}\right)$ of $x \mathrm{PbCl}_{2}-(30-x) \mathrm{PbO}-69 \mathrm{~B}_{2} \mathrm{O}_{3}-1 \mathrm{CuO}(x=5,10,15,20$ and $25 \mathrm{~mol} \%)$ glasses.

\begin{tabular}{|c|c|c|c|c|c|c|c|c|c|c|c|}
\hline \multirow[b]{2}{*}{ Glass } & \multicolumn{4}{|c|}{ Composition (mol\%) } & \multirow[b]{2}{*}{$\rho\left(\mathrm{g} \mathrm{cc}^{-1}\right)$} & \multirow{2}{*}{$\begin{array}{c}V_{\mathrm{m}} \\
\left(\mathrm{cc} \mathrm{mol}^{-1}\right)\end{array}$} & \multirow[b]{2}{*}{$\Delta E(\mathrm{eV})$} & \multirow[b]{2}{*}{$E_{\text {opt }}(\mathrm{eV})$} & \multirow[b]{2}{*}{$n$} & \multirow{2}{*}{$\begin{array}{c}R_{\mathrm{m}} \\
\left(\mathrm{cc} \mathrm{mol}^{-1}\right)\end{array}$} & \multirow{2}{*}{$\begin{array}{l}\alpha_{\mathrm{m}}\left(10^{-24}\right) \\
(\mathrm{cc} \mathrm{mol}-1)\end{array}$} \\
\hline & $\mathrm{PbCl}_{2}$ & $\mathrm{PbO}$ & $\mathrm{B}_{2} \mathrm{O}_{3}$ & $\mathrm{CuO}$ & & & & & & & \\
\hline РCPBC-1 & 5 & 25 & 69 & 1 & 4.358 & 35.75 & 0.670 & 2.46 & 2.50 & 22.84 & 9.04 \\
\hline РCPBC-2 & 10 & 20 & 69 & 1 & 4.180 & 37.93 & 0.267 & 2.69 & 2.47 & 22.69 & 8.98 \\
\hline РСРВC-3 & 15 & 15 & 69 & 1 & 4.025 & 40.07 & 0.285 & 2.80 & 2.44 & 24.70 & 9.78 \\
\hline РCPBC-4 & 20 & 10 & 69 & 1 & 3.882 & 42.26 & 0.347 & 3.06 & 2.39 & 24.50 & 9.70 \\
\hline РCPBC-5 & 25 & 5 & 69 & 1 & 3.754 & 44.43 & 0.295 & 3.20 & 2.35 & 31.72 & 12.56 \\
\hline
\end{tabular}

grade chemicals, boric acid $\left(\mathrm{H}_{3} \mathrm{BO}_{3}\right)$, lead chloride $\left(\mathrm{PbCl}_{2}\right)$, lead oxide $(\mathrm{PbO})$ and cupric oxide $(\mathrm{CuO})$ were taken as the initial starting materials. The glass mixture ratio for the present study is mentioned in table 1. Five grams of homogeneous batches were taken in porcelain crucible and sintered at $900^{\circ} \mathrm{C}$ for $45 \mathrm{~min}$ in an electrically heated furnace. The molten mixture was frequently stirred to get homogeneity and then, the melt was quenched. The obtained glasses were annealed at $200^{\circ} \mathrm{C}$ to remove thermal stress and strains. Thus formed glasses were bubble free, transparent and blue in colour and the thickness of the glass samples was $\approx 1 \mathrm{~mm}$. X-ray diffractograms (XRD) of the glass samples were recorded at room temperature (RT). Density measurements are carried out using Archimedes principle. The uncertainty in the measurement of density is \pm 0.001 . Polished glass samples were used for optical absorption measurements, which were carried out on Shimadzu UV-1800 series spectrometer at RT in the wavelength region of 200-1000 $\mathrm{nm}$ in absorbance mode. Electron paramagnetic resonance (EPR) spectra of the PCPBC glass series was recorded at RT using (BRUKER) EPR spectrometer operating at an X-band frequency $(9.7 \mathrm{GHz})$ with a modulating frequency of $100 \mathrm{kHz}$. The magnetic field was scanned from 2500-4000G. The approximate error in the values of $g$ and $A$ were about \pm 0.002 and $\pm 2 \times 10^{-4} \mathrm{~cm}^{-1}$, respectively. The Fourier transform infrared (FTIR) spectra of these samples are scanned in the range of 400-1600 $\mathrm{cm}^{-1}$ on Shimadzu 8400S FTIR spectrometer at RT. The micro Raman spectrum was recorded at RT using Jobin Yvon Horibra LABRAM-HR Raman spectrometer with Argon laser source of excitation wavelength of $488 \mathrm{~nm}$.

\section{Results and discussion}

\section{$3.1 X R D$}

Figure 1 presents the XRD patterns of the prepared glasses. The spectrum of each glass system was examined, which revealed the absence of Bragg peaks, indicating the amorphous nature of the glasses. The broad hump also suggests the presence of short range order.

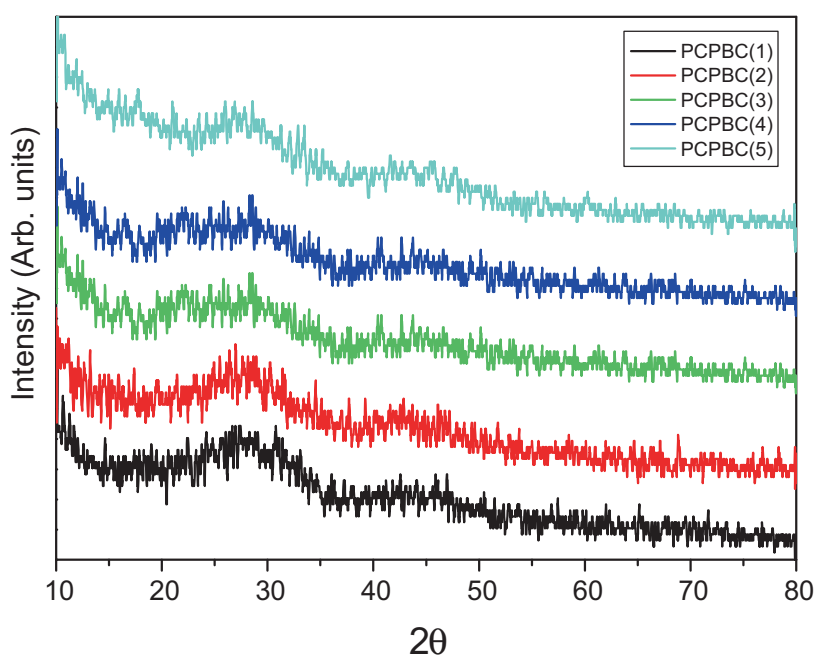

Figure 1. X-ray diffractograms of PCPBC glass system.

\subsection{Density and molar volume}

Density is the basic physical property, which explores the toughness and structural changes in any material. The variation of density depends on the coordination number, cross-link density, the size of interstitial positions and compactness [14]. Density $\left(\rho_{\text {exp }}\right)$ measurements were carried out using Archimedes principle

$$
\rho_{\exp }=\frac{W_{\mathrm{a}}}{W_{\mathrm{a}}-W_{\mathrm{b}}} \rho_{\mathrm{b}},
$$

where $W_{\mathrm{a}}$ and $W_{\mathrm{b}}$ are the weights in air and xylene of the sample, respectively, and $\rho_{\mathrm{b}}$ the density of xylene $\left(\rho_{\mathrm{b}}=0.865 \mathrm{~g}\right.$ $\left.\mathrm{cc}^{-1}\right)$. The molar volume $\left(V_{\mathrm{m}}\right)$ was estimated from the density and the molecular weight $(M)$ of the glass samples. The response of $\rho_{\exp }$ and $V_{\mathrm{m}}$ with compositional parameter $\mathrm{PbCl}_{2}$ is plotted in figure 2. It was found that the density decreases with increasing $\mathrm{PbCl}_{2}$ concentration, and molar volume showing exactly opposite behaviour. This variation is because of the ionic radius of chlorine $(1.81 \AA)$ is greater than oxygen $(1.4 \AA)$ and $\mathrm{Cl}^{-}$ion may occupy more space and spans 


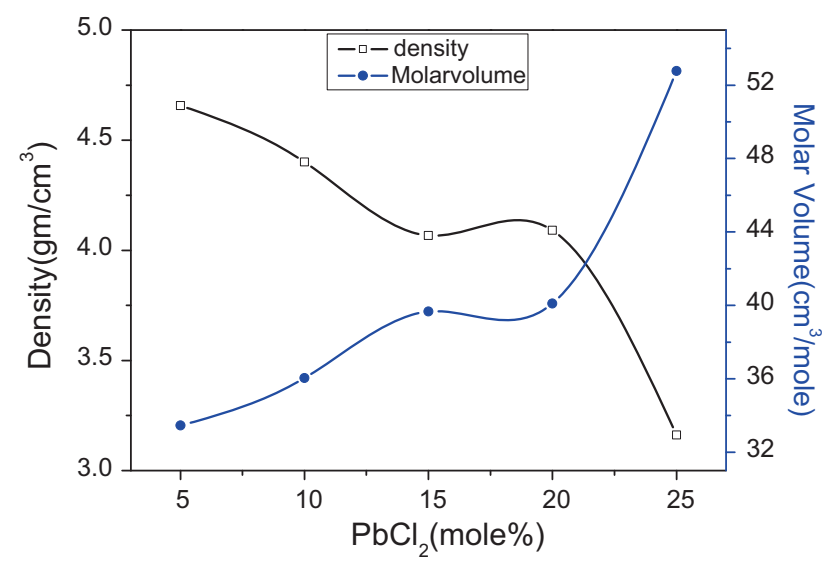

Figure 2. Variations of density and molar volume with $\mathrm{PbCl}_{2}$ content.

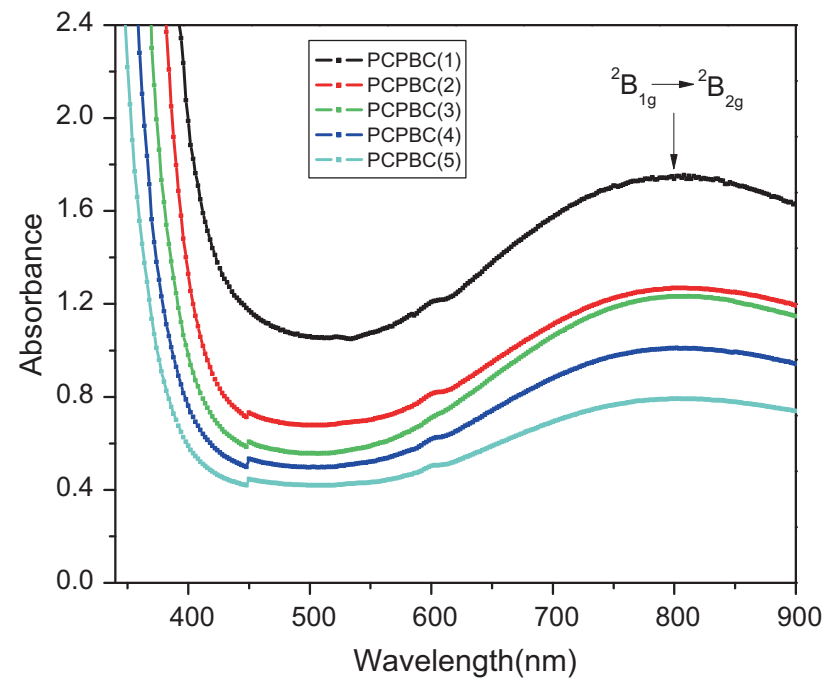

Figure 3. Optical absorption spectra of PCPBC glass system.

the glass network, thereby increasing molar volume. To accommodate the large $\mathrm{Cl}^{-}$ions, the glass network forms an open structure and the $\mathrm{Cl}^{-}$ions are located in the interstices $[15,16]$.

\subsection{Optical absorption spectra}

Figure 3 shows the spectra of optical absorption of all the glass compositions $x \mathrm{PbCl}_{2}-(30-x) \mathrm{PbO}-69 \mathrm{~B}_{2} \mathrm{O}_{3}-1 \mathrm{CuO}$. The broad absorption band in the spectra is assigned to ${ }^{2} \mathrm{~B}_{2 \mathrm{~g}} \rightarrow{ }^{2} \mathrm{~B}_{1 \mathrm{~g}}$ transition. No sharp absorption edges are found in the spectra, which further confirm the glassy nature. The absorption coefficient, $\alpha(v)$ is obtained for different photon energies using the relation;

$$
\alpha(v)=2.303 \frac{A}{d},
$$

where $A$ is the absorbance and $d$ is the thickness of the sample.

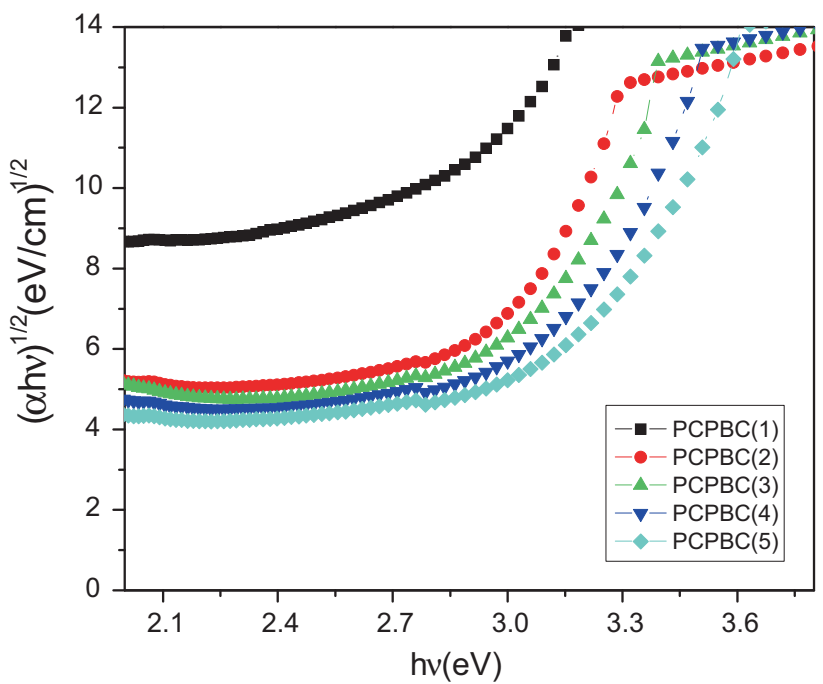

Figure 4. Tauc's plot of PCPBC glass system.

\subsection{Optical band gap and Urbach energy}

Figure 4 shows the Tauc's plot of prepared samples. The UV absorption edge is shifted to lower wavelength (i.e., blue-shifted) side with increase in $\mathrm{PbCl}_{2}$ content. According to Davis and Mott, optical band gap and photon energy are related as [17]:

$$
(\alpha h v)=B^{2}\left(h v-E_{\mathrm{g}}\right)^{\mathrm{r}}
$$

Physical quantities in the above equation have their usual meanings. Optical band gaps are obtained by extrapolating the linear region of the indirect allowed transition curve to $(\alpha h v)^{1 / 2}=0$. In the present study, optical band gap values are increasing with increase in $\mathrm{PbCl}_{2}$. The electro negativity of chlorine ion (3.16) is relatively smaller when compared with the electronegativity of oxygen ion (3.44). When $\mathrm{PbCl}_{2}$ content is increasing, the ionicity of oxygen ions decreases, and hence optical band gap increases $[15,18,19]$.

Urbach rule states that the absorption coefficient increases exponentially with photon energy [20-22]. Urbach's expression is given by

$$
\alpha(v)=C \exp (h v / \Delta E)
$$

where $C$ is a constant and $\Delta E$ the Urbach energy.

Urbach energy $(\Delta E)$ values were obtained by taking the inverse slopes of the straight line portion of the graph drawn between $\ln (\alpha)$ and $h v$. The nonlinear variation of Urbach energy $(\Delta E)$ with $\mathrm{PbCl}_{2}$ concentration is shown in figure 5. This nonlinear variation might be due to nonuniform distribution of defects in the glass matrix with increase of $\mathrm{PbCl}_{2}$. 


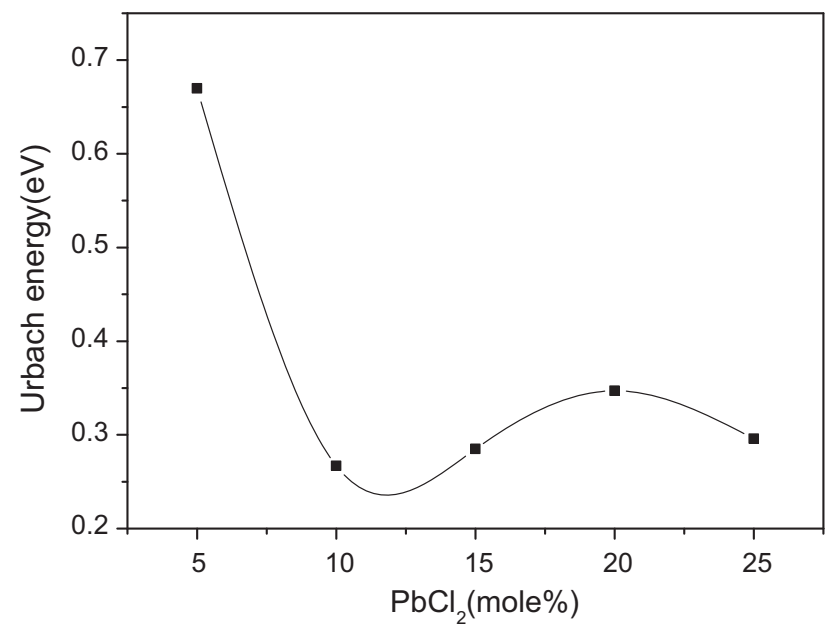

Figure 5. Variation of Urbach energy $(\Delta E)$ with $\mathrm{PbCl}_{2}$ content.

\subsection{Refractive index, molar refraction and molar electronic polarizability}

Dimitrova, Komatshu and Duffy [23-25] proposed a relation to evaluate the refractive index, molar refraction and molar polarizibility of the glasses, which are given below:

$$
\begin{aligned}
& \frac{n^{2}-1}{n^{2}+2}=1-\sqrt{\frac{E_{\mathrm{opt}}}{20}}, \\
& R_{\mathrm{M}}=\frac{n^{2}-1}{n^{2}+2} * V_{\mathrm{m}}, \\
& \alpha_{\mathrm{m}}=\left(\frac{3}{4 \Pi N_{\mathrm{A}}}\right) * R_{\mathrm{m}} .
\end{aligned}
$$

where $n$ is the refractive index, $V_{\mathrm{m}}$ the molar volume, the term $\left(n^{2}-1\right) /\left(n^{2}+2\right)$ represents the reflection loss and $N_{\mathrm{A}}$ the Avogadro's number. The $n$ values are in the range 2.73-2.35. From equation (5), it is clear that the refractive index values are decreasing with the increase in optical band gap, while from equations (6) and (7), molar refraction and electronic polarizability are proportionally increasing with molar volume. The evaluated values of refractive index, molar refraction and electronic polarizability of these glasses are given in table 1.

\subsection{EPR spectra}

A neutral copper atom with atomic number $Z=29$ has an electronic configuration $[\mathrm{Ar}] 3 \mathrm{~d}^{10} 4 \mathrm{~s}^{1}$. Copper atom acquires [Ar] $3 \mathrm{~d}^{9}$ configuration in its +2 oxidation state by losing one electron from $3 \mathrm{~d}$ and $4 \mathrm{~s}$ each and becomes $\mathrm{Cu}^{2+}$ ion. The effective spin of $\mathrm{Cu}^{2+}$ ion is $S=1 / 2$ and the nuclear spin $(I)$ is $3 / 2$. Hyperfine structure observed in the EPR spectrum is due to the interactions between the nuclear and electronic magnetic moments both in spin and orbital. Each fine structure line is expected to split into four hyperfine lines in accord with

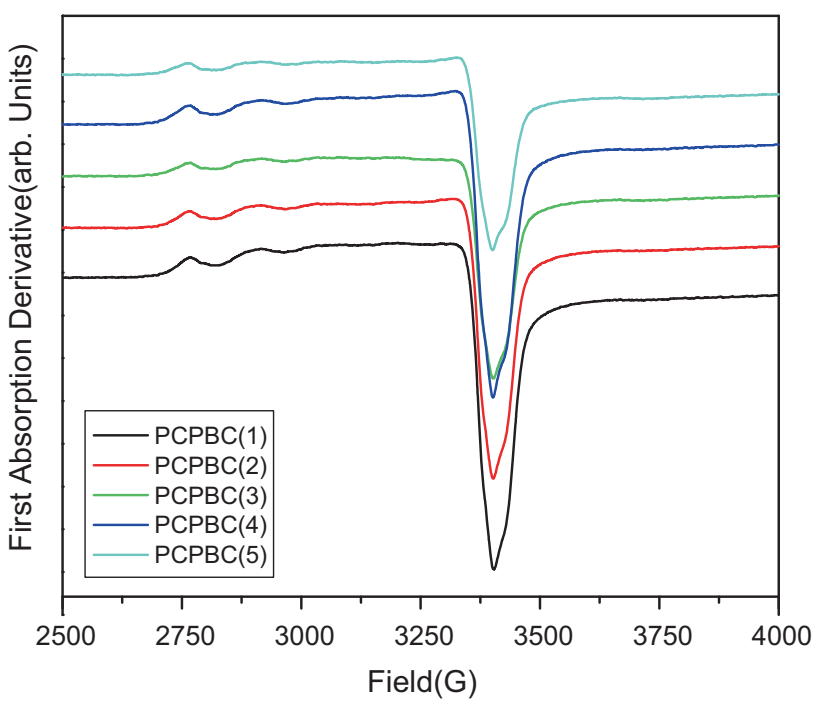

Figure 6. Electron paramagnetic resonance spectra of PCPBC glass system.

$2 I+1$. Figure 6 shows the EPR spectra of $x \mathrm{PbCl}_{2}-(30-x)$ $\mathrm{PbO}-69 \mathrm{~B}_{2} \mathrm{O}_{3}-1 \mathrm{CuO}$ glass system. In the present work, three weak parallel hyperfine splittings were observed in the range of 2750-3000G, while the fourth line merged with the perpendicular components. The analysis of EPR spectra is done using the spin-Hamiltonian [26].

$$
\begin{aligned}
\mathcal{H}= & \beta\left[g_{\|} H_{\mathrm{Z}} S_{\mathrm{Z}}+g_{\perp}\left(H_{\mathrm{X}} S_{\mathrm{X}}+H_{\mathrm{Y}} S_{\mathrm{Y}}\right)\right] \\
& +A_{\|} I_{\mathrm{Z}} S_{\mathrm{Z}}+A_{\perp}\left(I_{\mathrm{X}} S_{\mathrm{X}}+I_{\mathrm{Y}} S_{\mathrm{Y}}\right),
\end{aligned}
$$

where $Z$ is the symmetry axes of copper centres and other symbols have usual notations. The nuclear quadrapole interaction is so small to be considered in the analysis of the spectra. The expression for $g$ and $A$ tensors for parallel and perpendicular peaks are obtained from the solution of the spinHamiltonian [27], as

$$
\begin{aligned}
& h v=g_{\|} \beta H+m A_{\|}+\left(\frac{15}{4}-m^{2}\right) \frac{A_{\perp}^{2}}{2 g_{\|} \beta H}, \\
& h v=g_{\perp} \beta H+m A_{\perp}+\left(\frac{15}{4}-m^{2}\right) \frac{A_{\|}^{2}+A_{\perp}^{2}}{4 g_{\|} \beta H} .
\end{aligned}
$$

The spin-Hamiltonian parameters are given in table 2. The observed $g$ and $A$ values and shape of the EPR spectra suggest that the $\mathrm{CuO}$ in all the glasses is existing as $\mathrm{Cu}^{2+}$ ion with $3 \mathrm{~d}^{9}$ configurations. In the present work, it is noticed that $g_{\|}$values are varied from 2.338 (PCPBC1) to 2.464 (PCPBC5), a significant variation in $g_{\|}$values is observed. This might be due to the variation of ligand field strength around $\mathrm{Cu}^{2+}$ ion. $g_{\perp}$ values varied between 2.064 (PCPBC1) and 2.066 (PCPBC5) and are almost constant. $g_{\|}>g_{\perp}>g_{e}$ ( $g_{e}=2.0023$ ) and $A_{\mid}>A_{\perp}$ suggest that the environment 
Table 2. Spin-Hamiltonian parameters, number of spins, susceptibility and bonding parameters of $x \mathrm{PbCl}_{2}-(30-x) \mathrm{PbO}_{-}-69 \mathrm{~B}_{2} \mathrm{O}_{3}-1 \mathrm{CuO}$ (where $x=5,10,15,20$ and $25 \mathrm{~mol} \%$ ) glasses.

\begin{tabular}{lcccccccccc}
\hline Glass & $g_{\|}$ & $g_{\perp}$ & $A_{\|}\left(10^{-4} \mathrm{~cm}^{-1}\right)$ & $A_{\perp}\left(10^{-4} \mathrm{~cm}^{-1}\right)$ & $\Delta E_{\mathrm{xy}}\left(\mathrm{cm}^{-1}\right)$ & $\alpha^{2}$ & $\beta^{2}$ & $\beta_{1}^{2}$ & $\begin{array}{c}N\left(10^{21}\right) \\
\text { per kg }\end{array}$ & $\begin{array}{c}\chi\left(10^{-4}\right) \\
\left(\mathrm{m}^{3} \mathrm{~kg}^{-1}\right)\end{array}$ \\
\hline PCPBC-1 & 2.338 & 2.064 & 151 & 34 & 12873 & 0.825 & 0.717 & 0.789 & 2.61 & 4.73 \\
PCPBC-2 & 2.352 & 2.064 & 139 & 35 & 12801 & 0.805 & 0.735 & 0.833 & 2.99 & 5.43 \\
PCPBC-3 & 2.355 & 2.066 & 139 & 39 & 12252 & 0.805 & 0.735 & 0.797 & 3.11 & 5.67 \\
PCPBC-4 & 2.343 & 2.065 & 148 & 37 & 12478 & 0.819 & 0.722 & 0.775 & 2.66 & 4.83 \\
PCPBC-5 & 2.464 & 2.066 & 148 & 39 & 12331 & 0.944 & 0.627 & 0.910 & 3.07 & 5.78 \\
\hline
\end{tabular}

around $\mathrm{Cu}^{2+}$ ion is distorted octahedral $\left(\mathrm{D}_{4 \mathrm{~h}}\right)$ site elongated along $z$-axis [28]. The variation of $g_{\|}$and $A_{\|}$with $\mathrm{PbCl}_{2}$ content was found to be nonlinear, which suggest that there is a change in the tetragonal distortion around $\mathrm{Cu}^{2+}$ ion. For all the glass samples in the optical absorption spectra, a single asymmetric broadband near IR region was observed, which is shown in figure 3 . This band can be identified as the $d-d$ transition band due to $\mathrm{Cu}^{2+}$ ions and it is assigned to ${ }^{2} \mathrm{~B}_{1 \mathrm{~g}} \rightarrow{ }^{2} \mathrm{~B}_{2 \mathrm{~g}}$ transition $\left(\Delta E_{\mathrm{xy}}\right)$. Bonding between the orbitals of $\mathrm{Cu}^{2+}$ ion with its ligands are described by $\alpha^{2}, \beta^{2}$, and $\beta_{1}^{2} \cdot \alpha^{2}$ denote the in-plane $\sigma$-bonding of the ligand with $d_{x^{2}-y^{2}}$ orbital, the outof-plane and in-plane $\Pi$-bonding of ligands $\left(\beta^{2}\right.$ and $\left.\beta_{1}^{2}\right)$ with the $d_{\mathrm{xz}}, d_{\mathrm{yz}}$ and $d_{\mathrm{xy}}$ orbitals, respectively $[29,30]$. The bonding parameters are given in table 2 . The value of $\alpha^{2}$ indicates ionic nature of the $\sigma$-bond, while $\beta^{2}$ and $\beta_{1}^{2}$ indicate moderately ionic nature of the in-plane and out-of-plane $\pi$-bonds.

The number of unpaired spins $(N)$ of $\mathrm{Cu}^{2+}$ ions that are taking part in resonance can be estimated by comparing the area under the EPR spectra with that of standard spectra of $\mathrm{CuSO}_{4} \cdot 5 \mathrm{H}_{2} \mathrm{O}$ compound as given by Weil et al [31].

Using $N$ and $g$ values, we estimated the paramagnetic susceptibility of each glass sample by using the relation [32].

$$
\chi=\frac{N g^{2} \beta^{2} J(J+1)}{3 k_{\mathrm{B}} T}
$$

where $J=5 / 2$, and the other symbols in the expression have their usual notations. The $N$ and $\chi$ values are given in table 2 . Even though, the transition metal $(\mathrm{Cu})$ is fixed to $1 \mathrm{~mol} \%$, the number of spins participating in the resonance $(N)$ is varying nonlinearly with the compositional parameter $\mathrm{PbCl}_{2}$. It is understood that glass network plays a prominent role on $N$.

\section{$3.7 \quad F T I R$}

Structural and functional groups in amorphous solids are identified by FTIR and Raman studies [33-35]. FTIR spectra of $x \mathrm{PbCl}_{2}-(30-x) \mathrm{PbO}-69 \mathrm{~B}_{2} \mathrm{O}_{3}-1 \mathrm{CuO}$ (where $x=5,10,15$, 20 and $25 \mathrm{~mol} \%$ ) glasses are shown in figure 7 . The observed band positions and assignments of FTIR spectra are listed in table 3. The wavenumbers $<600 \mathrm{~cm}^{-1}$ (lower wavenumber side) are assigned to metallic cation vibrations in glasses

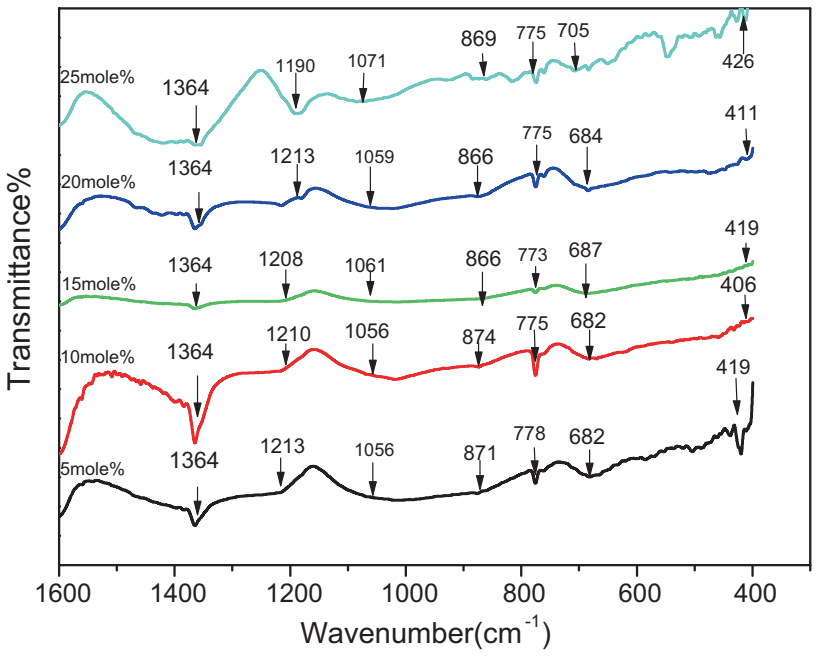

Figure 7. FTIR spectra of PCPBC glass system.

[35]. The observed band near $419 \mathrm{~cm}^{-1}$ is attributed to $\mathrm{Pb}^{2+}$ vibrations. Absorption bands observed in the range of 682 $705 \mathrm{~cm}^{-1}$ are due to B-O-B bond-bending vibrations from the pentaborate group or may be due to bending vibrations of $\mathrm{BO}_{3}$ triangles [6]. The band observed near $775 \mathrm{~cm}^{-1}$ is due to $\mathrm{O}_{3} \mathrm{~B}-\mathrm{O}-\mathrm{BO}_{4}$ bond-bending vibrations and at $870 \mathrm{~cm}^{-1}$ due to $\mathrm{B}-\mathrm{O}$ stretching vibrations in $\mathrm{BO}_{4}$ units from diborate rings [34]. A band near $1061 \mathrm{~cm}^{-1}$ is due to $\mathrm{B}-\varnothing$ stretching vibrations in $\emptyset_{4}^{-}$unit from tri-, tetra- and penta-borate groups. The bands that arise due to stretching vibrations of trigonal $\mathrm{BO}_{3}$ units from pyro- and ortho-borate groups are found near $1208 \mathrm{~cm}^{-1}$ and the presence of pyroborate and orthoborate groups containing $\mathrm{BO}_{3}^{-}$are found at $1364 \mathrm{~cm}^{-1}[33,35]$.

\subsection{Raman spectra}

Raman spectra of the glass samples are shown in figure 8 and corresponding deconvoluted spectrum of $\mathrm{PCPBC} 3$ is shown in figure 9. Raman spectra are spread over in the region of 400 $1600 \mathrm{~cm}^{-1}$. The Raman spectra have shown bands at $\sim 691$, 766, 796, 870, 955, 1051, 1114, 1246, 1335, $\sim 1415$ and $\sim 1502 \mathrm{~cm}^{-1}$ (table 3 ). The band at $\sim 691 \mathrm{~cm}^{-1}$ 
Table 3. Assignment of FTIR and Raman bands in the spectra of $x \mathrm{PbCl}_{2}-(30-x) \mathrm{PbO}-69 \mathrm{~B}_{2} \mathrm{O}_{3}-1 \mathrm{CuO}$ glass system.

\begin{tabular}{|c|c|c|c|}
\hline \multicolumn{2}{|r|}{ FTIR } & \multicolumn{2}{|r|}{ Raman } \\
\hline $\begin{array}{l}\text { Wavenumber } \\
\qquad\left(\mathrm{cm}^{-1}\right)\end{array}$ & Assignment & $\begin{array}{l}\text { Wavenumber } \\
\qquad\left(\mathrm{cm}^{-1}\right)\end{array}$ & Assignment \\
\hline$\sim 419$ & $\mathrm{~Pb}^{2+}$ vibrations & $\sim 691$ & Existence of $\mathrm{BO}_{2} \mathrm{O}_{2}^{3-}$ unit \\
\hline$\sim 687$ & $\begin{array}{l}\mathrm{B}-\mathrm{O}-\mathrm{B} \text { bond-bending vibrations from } \\
\text { pentaborate group or bending vibrations } \\
\text { of } \mathrm{BO}_{3} \text { traingles }\end{array}$ & $\sim 766$ & $\begin{array}{l}\text { Symmetric breathing vibrations of } \\
\text { six-member rings with one or two } \mathrm{B} \emptyset_{3} \\
\text { triangles replaced by } \mathrm{B} \varnothing_{4}^{-} \text {tetrahedra. }\end{array}$ \\
\hline$\sim 775$ & $\mathrm{O}_{3} \mathrm{~B}-\mathrm{O}-\mathrm{BO}_{4}$ bond-bending vibrations & $\sim 796$ & $\begin{array}{l}\text { Symmetric breathing vibrations of boroxol } \\
\text { rings. }\end{array}$ \\
\hline$\sim 866$ & $\begin{array}{l}\mathrm{B}-\mathrm{O} \text { stretching vibrations in } \mathrm{BO}_{4} \text { units } \\
\text { from diborate rings }\end{array}$ & $\sim 870$ & $\begin{array}{l}\text { Symmetric stretching vibrations of } \mathrm{B}-\mathrm{O}-\mathrm{B} \\
\text { bridges in pyroborate units. }\end{array}$ \\
\hline$\sim 1061$ & $\begin{array}{l}\mathrm{B}-\mathrm{O} \text { stretching vibrations in } \mathrm{BO}_{4} \text { units } \\
\text { from tri-, tetra- and penta-borate groups }\end{array}$ & $\sim 955$ & Due to pentaborate and tetraborate groups \\
\hline$\sim 1208$ & $\begin{array}{l}\text { Stretching vibrations of tetragonal } \mathrm{BO}_{3} \\
\text { units from pyroborate and orthoborate } \\
\text { groups }\end{array}$ & $\sim 1051$ & Attributed to presence of diborate groups \\
\hline \multirow[t]{5}{*}{$\sim 1364$} & $\begin{array}{l}\text { Presence of pyroborate and orthoborate } \\
\text { groups containing } \mathrm{BO}_{3}^{-}\end{array}$ & $\sim 1114$ & Diborate groups \\
\hline & & $\sim 1246$ & Pyroborate groups \\
\hline & & $\sim 1335$ & $\mathrm{~B} \varnothing_{2} \mathrm{O}^{-}$triangles linked to $\mathrm{B} \varnothing_{4}^{-}$units \\
\hline & & $\sim 1415$ & $\begin{array}{l}\text { Stretching of B-O bands attached to large } \\
\text { number of borate groups }\end{array}$ \\
\hline & & $\sim 1502$ & $\begin{array}{l}\mathrm{B}_{2} \mathrm{O}^{-} \text {triangles linked to other borate } \\
\text { triangular units }\end{array}$ \\
\hline
\end{tabular}

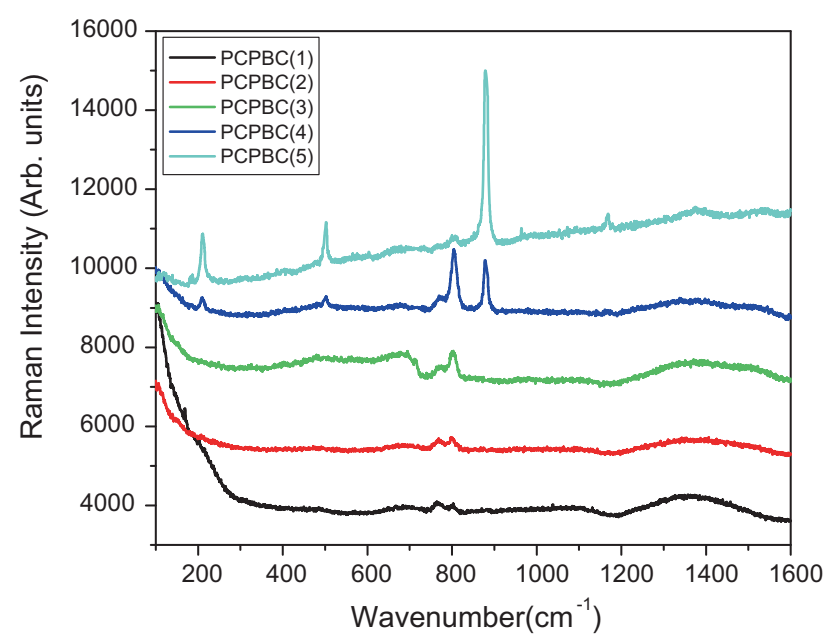

Figure 8. Raman spectra of PCPBC glass system.

shows the existence of $\mathrm{BO}_{2} \mathrm{O}_{2}^{3-}$ unit [38]. The band centred at $\sim 766 \mathrm{~cm}^{-1}$ can be assigned to symmetric breathing vibrations of six-member rings with one or two $\mathrm{B} \emptyset_{3}$ triangles replaced by $\mathrm{B} \emptyset_{4}^{-}$tetrahedra. The band at $\sim 796 \mathrm{~cm}^{-1}$ is assigned to symmetric breathing vibrations of boroxol rings, it is shifting towards higher wavenumber side (i.e., $796-806 \mathrm{~cm}^{-1}$ ) and its intensity is increasing with the increase of $\mathrm{PbCl}_{2}$ content. The band at $\sim 870 \mathrm{~cm}^{-1}$ is due to symmetric stretching vibrations

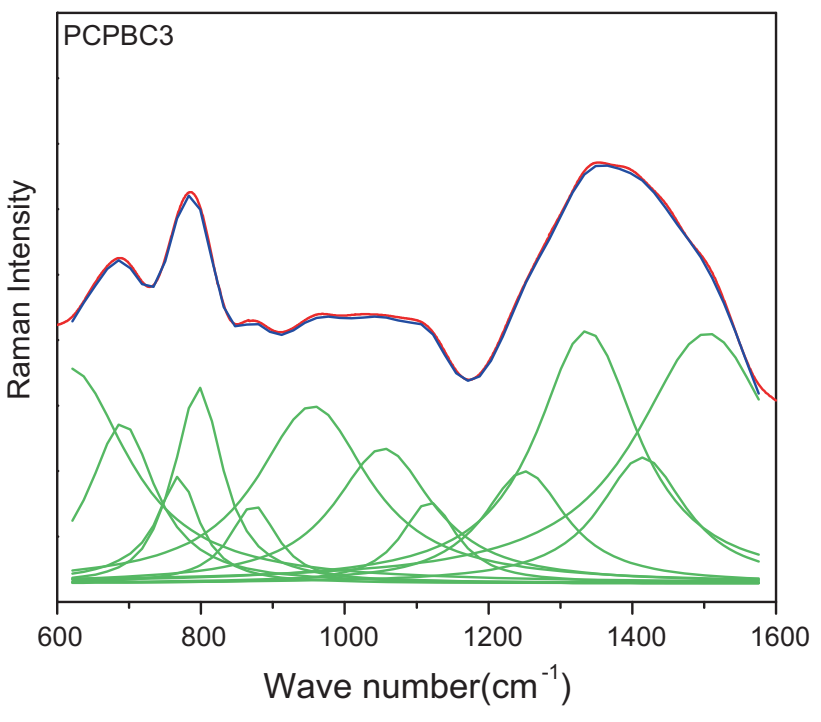

Figure 9. Deconvoluted Raman spectra of $\mathrm{PCPBC} 3$ glass.

of B-O-B bridges in pyroborate units and it is shifted to 880 $\mathrm{cm}^{-1}$ with increasing intensity for 20 and $25 \mathrm{~mol} \%$ of $\mathrm{PbCl}_{2}$ $[34,38]$. As $\mathrm{PbCl}_{2}$ content is increasing, the peak intensity of $796 \mathrm{~cm}^{-1}$ is increasing, which might be due to the formation of pentaborate groups [39]. For 20 and $25 \mathrm{~mol} \%$ of $\mathrm{PbCl}_{2}$, a new band at $500 \mathrm{~cm}^{-1}$ appeared, which is also confirming the 
formation of pentaborate group. The band at $\sim 955 \mathrm{~cm}^{-1}$ is due to pentaborate and tetraborate groups. The band around $\sim 1051 \mathrm{~cm}^{-1}$ is attributed to the presence of diborate groups. The bands at $\sim 1114$ and $\sim 1246 \mathrm{~cm}^{-1}$ are due to diborate and pyroborate groups, respectively. The band at $\sim 1335 \mathrm{~cm}^{-1}$ is due to $\mathrm{B}_{2} \mathrm{O}^{-}$triangles linked to $\mathrm{B} \emptyset_{4}^{-}$units. The band at $\sim 1415 \mathrm{~cm}^{-1}$ is assigned to stretching of $\mathrm{B}-\mathrm{O}$ bands attached to the large number of borate groups and at $\sim 1502 \mathrm{~cm}^{-1}$ due to $\mathrm{B}_{2} \mathrm{O}^{-}$triangles linked to other borate triangular units [34-41].

\section{Conclusions}

$x \mathrm{PbCl}_{2}-(30-x) \mathrm{PbO}-69 \mathrm{~B}_{2} \mathrm{O}_{3}-1 \mathrm{CuO}$ (where $x=5,10,15$, 20 and $25 \mathrm{~mol} \%$ ) glasses were prepared by the melt quenching method. From XRD spectra, the amorphous nature of the glasses was confirmed. Molar volume is increasing, while the density is decreasing with the increase of $\mathrm{PbCl}_{2}$ since ionic radius of chlorine ion is greater than oxygen. A broad absorption band is observed in the optical absorption spectra, which were assigned to ${ }^{2} \mathrm{~B}_{1 \mathrm{~g}} \rightarrow{ }^{2} \mathrm{~B}_{2 \mathrm{~g}}$ transition. Optical band gap values are increasing with $\mathrm{PbCl}_{2}$ content, which is due to the decrease in iconicity of oxygen ions with $\mathrm{PbCl}_{2}$ content. From the EPR spectra, it was concluded that the ground state of $\mathrm{Cu}^{2+}$ ion is $d_{x^{2}-y^{2}}$ orbital $\left({ }^{2} \mathrm{~B}_{1 \mathrm{~g}}\right.$ state), the $\mathrm{Cu}^{2+}$ ions were located in tetragonally distorted octahedral sites. FTIR spectra of all the glasses showed bands in the mid-infrared region of 400-1600 $\mathrm{cm}^{-1}$. The observed bands are assigned and some of the bands are attributed to $\mathrm{B}-\mathrm{O}-\mathrm{B}$ bond bending vibrations and stretching vibrations of $\mathrm{BO}_{3}, \mathrm{BO}_{4}$ units from various borate groups. Raman spectra of all the glasses exhibited bands in the region of $400-1600 \mathrm{~cm}^{-1}$. These bands are attributed to the presence of diborate and pyroborate groups and some of these bands exhibit symmetric breathing vibrations of six-membered rings and boroxol rings.

\section{References}

[1] Dahiya M S, Khasa S and Agarwal A 2015 J. Asian Ceram. Soc. 3206

[2] Upender G, Ramesh S, Prasad M, Sathe V G and Mouli V C 2010 J. Alloys Compd. 504468

[3] Ignatieva L N, Savchenko N N, Yu Marchenko V, Maslennikova I G and Zverev G A Goncharuk 2016 J. Non-Cryst. Solids 450 103

[4] Rao K J, Rao B G and Elliott S R 1985 J. Mater. Sci. 201678

[5] Laxmikanth C, Raghavaiah B V, Appa Rao B and Veeraiah N 2004 J. Lumin. 109193

[6] Saddeek Yasser B 2017 Bull. Mater. Sci. 40545

[7] Saddeek Yasser B 2009 J. Alloys Compd. 46714

[8] Yousef E S S 2007 J. Mater. Sci. 424502

[9] Pisarska J, Zur L and Wojciech W A 2012 Phys. Status Solidi A 2091134
[10] Ghoneim N A, El Batal H A, Abdelghany A M and Ali I S 2011 J. Alloys Compd. 5096913

[11] Pisarski W A, Pisarska J, Lisiecki R, Grobelny Ł, DominiakDzik G and Ryba-Romanowski W 2009 Chem. Phys. Lett. 472 217

[12] Shareefuddin Md, Jamal Md and Narasimha Chary M 1995 Phys. Status Solidi A 148 K37

[13] Thulasiramudu A and Buddhudu S 2006 J. Quant. Spectrosc. Radiat. Transf. 97181

[14] Saddeek Yasser B, Aly K A and Bashier S A 2010 Physica B 4052407

[15] Chandra Sekhar K, Hameed A, Ramadevudu G, Narasimha Chary M and Shareefuddin Md 2017 Mod. Phys. Lett. B 31 1750180

[16] El Damravi G 1994 J. Non-Cryst. Solids 17691

[17] Davis A and Mott N F 1970 Philos. Mag. 22903

[18] John Duffy A 2001 Phys. Chem. Glasses 42151

[19] Sebastian Shajo and Abdul Khadar M 2004 Bull. Mater. Sci. 27207

[20] Tauc J, Grigorovice R and Vancu A 1966 Phys. Status Solidi 15 627

[21] Talib Z A, Daud W M, Tarmizi E Z M, Sidek H A A and Yunus W M M 2008 J. Phys. Chem. Solids 691969

[22] Urbach F 1953 Phys. Rev. 921324

[23] Dimitrov V and Sakka S 1996 J. Appl. Phys. 791736

[24] Dimitrov V and Komatshu T 2002 J. Solid State Chem. 163 100

[25] Duffy J A 1986 J. Solid State Chem. 62145

[26] Kivelson D and Neiman R 1961 J. Chem. Phys. 35149

[27] Bleaney B, Bowers K D and Pryce M H L 1955 Proc. R Soc. A 228147

[28] Thirumala Rao G, Babu B, Joyce Stella R, Pushpa Manjari V and Ravikumar R V S S N 2015 Spectra Acta Part A 139 86

[29] Sands R H 1955 Phys. Rev. 991222

[30] Shareefuddin Md, Jamal Mohd and Narasimha Chary M 1996 J. Non-Cryst. Solids 20195

[31] Weil J A, Bolton J R and Wertz J E 1994 Electron paramagnetic resonance elementary theory and practical applications (New York: Wiley) p 498

[32] Aschcroft N W and Mermin N D 2001 Solid State Physics (New York: Harcourt College Publishers) p 656

[33] Doweidar H and Saddeek Yasser B 2009 J. Non-Cryst. Solids $\mathbf{3 5 5} 348$

[34] Ciceo-Lucacel R and Ardelean I 2007 J. Non-Cryst. Solids 353 2020

[35] Sumalatha B, Omkaram I, Rajavardhana Rao T and Linga Raju Ch 2013 Physica B 41199

[36] Saddeek Y B 2009 Philos. Mag. 8941

[37] Dwivedi B P and Khanna B N 1995 J. Phys. Chem. Solids 56 36

[38] Meera B N and Ramakrishna J 1993 J. Non-Cryst. Solids 1591

[39] Meera B N, Sood A K, Chandrabhas N and Ramakrishna J 1990 J. Non-Cryst. Solids 126224

[40] Padmaja G and Kistaiah P 2009 J. Phys. Chem. A 113 2397

[41] Naresh V and Buddhudu S 2012 Ceram. Inter. 38 2325 